\title{
¿Interannual Relationship between the Boreal Spring Arctic Oscillation and the Northern Hemisphere Hadley Circulation Extent
}

\author{
DINGZHU HU \\ Key Laboratory of Meteorological Disasters of China Ministry of Education/Joint International Research Laboratory of \\ Climate and Environment Change/Collaborative Innovation Center on Forecast and Evaluation of Meteorological \\ Disasters, Nanjing University of Information Science and Technology, Nanjing, China \\ Yi-Peng GuO AND ZHE-Min TAN \\ Key Laboratory of Mesoscale Severe Weather/Ministry of Education, and School of Atmospheric Sciences, Nanjing \\ University, Nanjing, China

\section{ZHAOYONG GUAN} \\ Key Laboratory of Meteorological Disasters of China Ministry of Education/Joint International Research Laboratory of \\ Climate and Environment Change/Collaborative Innovation Center on Forecast and Evaluation of Meteorological \\ Disasters, Nanjing University of Information Science and Technology, Nanjing, China
}

(Manuscript received 1 October 2018, in final form 17 April 2019)

\begin{abstract}
This study investigates the interannual relationship and the dynamical linkage between the boreal spring Arctic Oscillation (AO) and the Northern Hemisphere Hadley circulation extent (HCE). The spring AO is positively correlated with the $\mathrm{HCE}$, with one standard positive deviation of the AO index corresponding to approximately $0.42^{\circ}$ latitude poleward shift of the HCE. The interaction between the planetary wave and the zonal winds over the subtropics results in an anomalous eddy momentum flux divergence, which shifts the HCE poleward. The AO related transient eddy momentum flux divergence makes nearly 2 times larger contributions than those of the stationary component to the HCE change. The increased equatorward transient wave flux over the subtropics is possibly related to the larger meridional gradient of the transient wave refractive index there. The AO positive phase corresponds to an enhanced planetary wave propagation from the midlatitude Atlantic Ocean to the subtropics, which resembles the North Atlantic Oscillation pattern. The autumn and winter AO-HCE relationship is similar to that during spring, while summer has the weakest relationship, which could be mainly attributed to the far poleward extension of the climatological HCE during summer.
\end{abstract}

\section{Introduction}

The Hadley circulation (HC) is a thermally driven large-scale circulation in the tropics, which lifts the warm and moist air near the equator and sinks in the subtropics (e.g., Hadley 1735; Glickman 2000). The sinking air suppresses convection in the subtropics, generating subtropical dry zones. The HC extent (HCE), which indicates the boundary of the sinking air,

¿ Denotes content that is immediately available upon publication as open access.

Corresponding author: Yi-Peng Guo, guoyp@nju.edu.cn is an important proxy of the tropical extent. Thus, the variations of the HCE in both hemispheres are important to the changes in the subtropical atmospheric circulation, precipitation recycling, and droughts (e.g., Lu et al. 2007, 2010; Kang et al. 2011; Polvani et al. 2011; Bony et al. 2013).

Observational and modeling studies have verified that the tropics have experienced a poleward expansion during the last three decades (e.g., Fu et al. 2006; Hu and Fu 2007; Seidel and Randel 2007; Johanson and Fu 2009; Ceppi and Hartmann 2013; Adam et al. 2014; Allen et al. 2014; Lucas et al. 2014), as evidenced by a poleward shift of the HCE. Several factors are recognized to have influences on the poleward shift of HCE, such as the 
stratospheric ozone depletion (e.g., Son et al. 2009, 2010; Polvani et al. 2011; Orr et al. 2012; Waugh et al. 2015), greenhouse gas emissions (e.g., Tao et al. 2016), anthropogenic aerosols (e.g., Allen et al. 2012, 2014), and sea surface temperature (SST) changes (e.g., Adam et al. 2014; Allen et al. 2014). These factors can influence the HCE either by modifying the meridional temperature gradient according to the theory of nearly inviscid flow (Held and Hou 1980) or by modulating the midlatitude eddies due to the small Rossby number (Ro) in the subtropics (e.g., Schneider 2006; Walker and Schneider 2006). Son and Lee (2005) suggested that the midlatitude baroclinic zone width is a key parameter in determining the jet structure, thus it is an important metric to evaluate the HCE. Comparatively, the HC expansion is more detectable in the Southern Hemisphere ( $\mathrm{SH})$ than in the Northern Hemisphere (NH), partly because the stratospheric ozone depletion is most significant over the Antarctic (e.g., Garfinkel et al. 2015). During the austral summer, the ozone depletion in Antarctic stratosphere has significant impacts on the $\mathrm{HC}$ expansion through modulating the midlatitude eddies, which results in a substantial poleward shift of the midlatitude jet and increased subtropical precipitation (e.g., Son et al. 2009, 2010; Polvani et al. 2011; Orr et al. 2012). It can be seen that these previous studies mostly focused on the SH. However, the magnitude of the interannual variation of the HCE is larger than that of the long-term trend (e.g., Nguyen et al. 2013; Adam et al. 2014; Guo and Li 2016), which may affect the interannual variability of the subtropical weather and climate in the NH. Thus, it is important to understand how the NH HCE changes on interannual time scale, as well as the underlying dynamical mechanisms.

As the dominant mode of $\mathrm{NH}$ extratropical variability, the boreal spring Arctic Oscillation (AO) is primarily driven by midlatitude eddies and has significant impacts on $\mathrm{NH}$ climate in both the tropics and extratropics (e.g., Thompson and Wallace 2000; Thompson et al. 2000, 2003; Vallis et al. 2004; Nakamura et al. 2006; Gong et al. 2011; Chen et al. 2014a, 2017). The spring AO is connected to the climate variability such as precipitation, tropopause height, and total column ozone via the planetary wave activity (e.g., Thompson and Wallace 2000; Thompson et al. 2000) and it also has a close relationship with the HCE in the NH (e.g., Nakamura et al. 2006; Nguyen et al. 2013). However, the dynamical linkages for how the AO connects to the $\mathrm{HCE}$ in the $\mathrm{NH}$ still remain unclear.

In the above context, this study focuses on the interannual relationship and the dynamical linkages between the boreal spring $\mathrm{AO}$ and the HCE in the NH. Following this introduction, section 2 introduces the datasets and methods used in the study. Section 3 analyzes the statistical relationship between the boreal spring AO and the HCE. Section 4 further investigates the dynamical linkages. Section 5 discusses the seasonal difference of the AO-HCE relationship and section 6 presents the conclusions and discussion.

\section{Datasets and methods}

\section{a. Datasets}

In this study, we adopted the monthly mean atmospheric variables, including sea level pressure (SLP), meridional and zonal winds, air temperature, and geopotential height, derived from the National Centers for Environmental Prediction-Department of Energy Atmospheric Model Intercomparison Project II reanalysis (NCEP-2) data (Kanamitsu et al. 2002) from 1979 to 2014 , which has a horizontal resolution of $2.5^{\circ} \times 2.5^{\circ}$ in longitude and latitude with 17 vertical levels. The European Centre for Medium-Range Weather Forecasts interim reanalysis (ERA-Interim) dataset from 1979 to 2014 , which has a horizontal resolution of $0.75^{\circ} \times 0.75^{\circ}$ in longitude and latitude and 37 vertical layers (Dee et al. 2011), was also employed to validate the NCEP-2 data. The sea surface temperature dataset was from the Extended Reconstructed SST version 3b (ERSST v3b) reanalysis from NOAA with a horizontal resolution of $2.0^{\circ} \times 2.0^{\circ}$ in longitude and latitude (Smith et al. 2008). The daily horizontal winds and the potential temperature were employed from NCEP-2 to derive the transient component of the eddy momentum flux. The transient components of the zonal and meridional winds are defined as their daily deviations from the monthly means.

\section{b. Methods}

The mass streamfunction (MSF) was employed to depict the $\mathrm{HC}$, which is derived by vertically integrating the zonal mean meridional winds (e.g., Holton 1994; Oort and Yienger 1996). The MSF is calculated as follows:

$$
\psi=\int \frac{2 \pi a \cos \varphi}{g}[\bar{v}] d p
$$

where $v$ denotes the meridional wind, $a$ is the radius of Earth, $\varphi$ is the latitude, $g$ is the acceleration due to gravity, and $p$ is atmospheric pressure. The overbar and square brackets in this study indicate the monthly and zonal means, respectively. The HCE is defined as the 
latitude where the 500-hPa MSF reaches zero (e.g., Hu and $\mathrm{Fu}$ 2007; Adam et al. 2014).

The planetary wave is measured by the quasigeostrophic Eliassen-Palm (EP) flux and its divergence (Edmon et al. 1980). The two-dimensional EP flux and its divergence are given as follows:

$$
\begin{aligned}
F_{\varphi} & =-a \cos \varphi\left[v^{*} u^{*}\right], \\
F_{p} & =\frac{a \cos \varphi f}{d[\theta] / d p}\left[v^{*} \theta^{*}\right], \\
\operatorname{Div} & =\frac{1}{a \cos \varphi} \frac{\partial}{\partial \varphi}\left(F_{\varphi} \cos \varphi\right)+\frac{\partial}{\partial p} F_{p} .
\end{aligned}
$$

Here, $F_{\varphi}$ and $F_{p}$ are the meridional and vertical components of the EP flux, respectively; Div is the EP flux divergence; $f$ is the Coriolis parameter; $u$ is the zonal wind; $\theta$ is the potential temperature; and the asterisks denote the departure from the zonal mean. The other parameters are the same as those in Eq. (1). The daily datasets were used to calculate the total EP flux for each day, which is averaged to obtain the monthly total EP flux. The monthly mean datasets were used to calculate the stationary EP flux. The transient EP flux was obtained by subtracting the stationary component from the total monthly EP flux.

We also adopted the horizontal components of the wave activity analysis following Plumb (1985):

$$
F_{s}=p \cos \varphi\left\{\begin{array}{c}
\frac{1}{2 a^{2} \cos ^{2} \varphi}\left[\left(\frac{\partial \Psi^{*}}{\partial \lambda}\right)^{2}-\Psi^{*} \frac{\partial^{2} \Psi^{*}}{\partial \lambda^{2}}\right] \\
\frac{1}{2 a^{2} \cos \varphi}\left(\frac{\partial \Psi^{*}}{\partial \lambda} \frac{\partial \Psi^{*}}{\partial \varphi}-\Psi^{*} \frac{\partial^{2} \Psi^{*}}{\partial \lambda \partial \varphi}\right)
\end{array}\right\},
$$

where $F_{s}$ is the horizontal wave activity flux, $\Psi^{*}$ is the perturbed streamfunction, and $\lambda$ is the longitude. The other parameters are the same as those in the above equations. This wave activity flux is parallel to the group velocity of the stationary Rossby waves, and can well represent the direction of horizontal wave propagation in the atmosphere.

The quasigeostrophic refractive index (RI) is employed to interpret the effect of the changes in the large-scale circulation on the wave propagation. It is defined as (Chen and Robinson 1992)

$$
\mathrm{RI}=\frac{\bar{q}_{\varphi}}{\bar{u}-c}-\left(\frac{k}{a \cos \varphi}\right)^{2}-\left(\frac{f}{2 N H}\right)^{2},
$$

where $\bar{q}_{\varphi}=(2 \Omega / a) \cos \varphi-\left(1 / a^{2}\right)\left[(\bar{u} \cos \varphi)_{\varphi} / \cos \varphi\right]_{\varphi}-$ $\left(f^{2} / \rho_{0}\right)\left(\rho_{0}\left[\overline{u_{z}} / N^{2}\right]\right)_{z}$ is the meridional gradient of the zonal mean potential vorticity; $c=\sigma a \cos \varphi / k$ is the phase speed; $k$ is the zonal wavenumber; $\sigma$ is the wave frequency; $\rho_{0}$ is the background density of the atmosphere; $N^{2}$ is the buoyancy frequency; $H$ is the scale height $(\sim 7 \mathrm{~km})$; and $\Omega$ is Earth's angular frequency. The other parameters are the same as those in the above equations. The RI is treated as the stationary wave RI when the wave frequency $\sigma$ is zero $\left(c=0 \mathrm{~m} \mathrm{~s}^{-1}\right)$ and as the transient wave RI when $\sigma$ is nonzero $\left(c \neq 0 \mathrm{~m} \mathrm{~s}^{-1}\right)$.

As our focus was on the interannual time scale, all the variables were subjected to a 9-yr high-pass Lanczos filter (Duchon 1979). We define the AO index as the principal component (PC) of the first empirical orthogonal function (EOF) mode of the SLP anomalies in the $\mathrm{NH}$ extratropics $\left(20^{\circ}-90^{\circ} \mathrm{N}\right)$ following previous studies (e.g., Thompson and Wallace 1998, 2000). To reduce ENSO's contamination in the results, the ENSO signals were removed from all the variables by subtracting the anomalies linearly regressed on the Niño-3.4 index (defined as the SST anomalies averaged over the region $\left.5^{\circ} \mathrm{S}-5^{\circ} \mathrm{N}, 170^{\circ}-120^{\circ} \mathrm{W}\right)$. The correlation and regression methods were used, and the two-tailed Student's $t$ test was applied to evaluate the statistical significance.

\section{The relationship between the spring $\mathrm{AO}$ and Northern Hemisphere HCE}

Figure 1 first shows EOF-1 mode of the boreal spring [March-May (MAM)] SLP anomalies of the NH, the standardized NH HCE, and the AO index during 19792014 based on NCEP-2 and ERA-Interim, respectively. The EOF-1 modes exhibit annular seesaw patterns with positive and negative anomalies in the mid- and high latitudes, respectively (Figs. 1a,c). The positive SLP anomalies have two maximum centers, which are located over the North Pacific and North Atlantic regions, respectively, while the negative SLP anomalies center in the polar region. This spring AO pattern agrees well with previous studies (e.g., Thompson and Wallace 1998, 2000; Thompson et al. 2003; Chen et al. 2014a). The AO indices from the NCEP-2 and ERA-Interim have a correlation coefficient of $0.99(p<0.001)$, which indicates that the AO signal can be reliably captured by both the datasets. Figure 1 also indicates that the spring normalized HCE is positively correlated with the spring AO index with correlation coefficients of $0.43(p<0.01)$ and $0.46(p<0.01)$ for NCEP-2 and ERA-Interim, respectively (Figs. 1b,d). Quantitatively, one standard deviation's increase in the AO index corresponds to approximate $0.42^{\circ}$ latitude poleward shift of the HCE, which is obtained by linearly regressing the HCE on the standardized AO index. In the following section, the dynamical linkages between $\mathrm{AO}$ and the HCE will be investigated. 
(a) NCEP-2
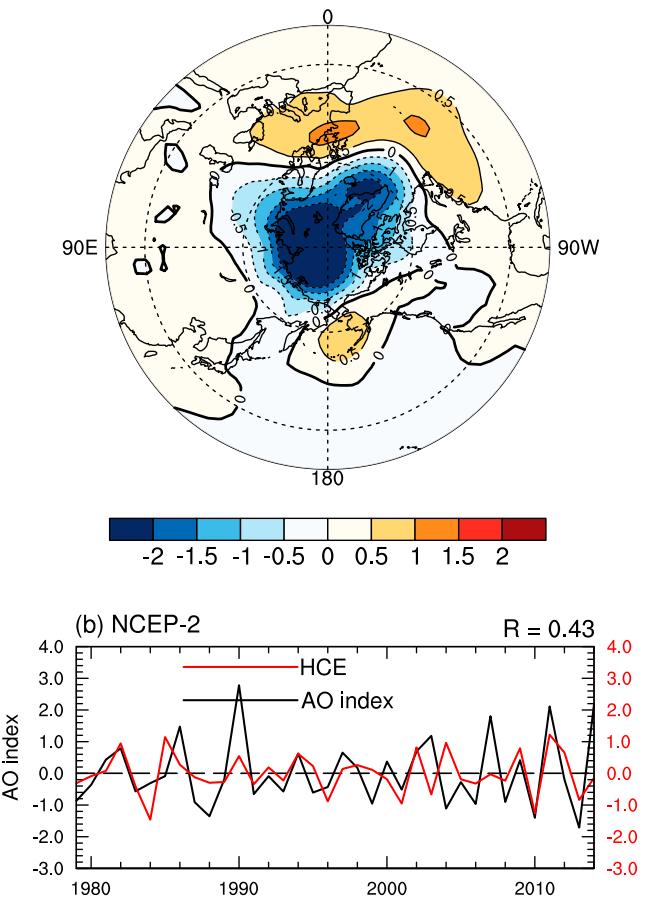

(c) ERA-Interim
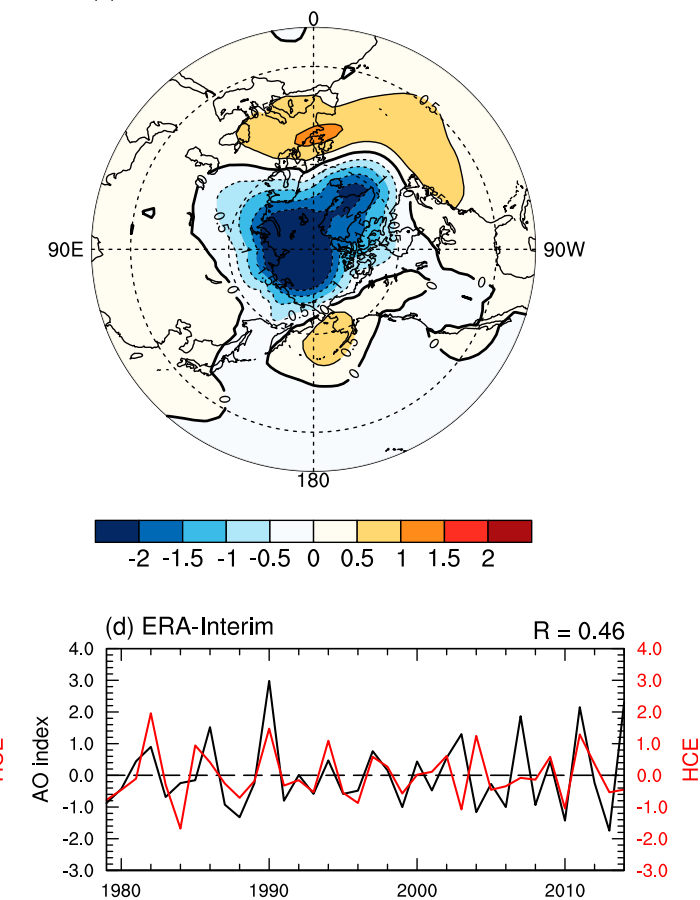

FIG. 1. (a) The EOF-1 mode of the spring SLP anomalies (units: hPa) over the Northern Hemisphere $\left(20^{\circ}-90^{\circ} \mathrm{N}\right)$ during 1979-2014 based on NCEP-2. (b) Evolutions of the first principal component (PC-1) of the EOF-1 mode of the SLP anomalies (black line) and the standardized HCE (red line). (c),(d) As in (a),(b), but for ERA-Interim.

\section{Dynamical linkages between the AO and the Northern Hemisphere HCE}

\section{a. Atmospheric circulation anomalies associated with eddy momentum budget}

Figure 2 shows the MSF climatology and its anomalies regressed on the $\mathrm{AO}$ index in spring during the period
1979-2014 in the NH. The MSF anomalies regressed on the AO index correspond to one standard deviation of AO index, which apply to all the regressed anomalies in this study. The climatological MSF shows that the northern cell of the $\mathrm{HC}$ with the upward branch in the equatorial region and downward branch around $30^{\circ} \mathrm{N}$. The MSF anomalies regressed on the AO index exhibit (a) NCEP-2

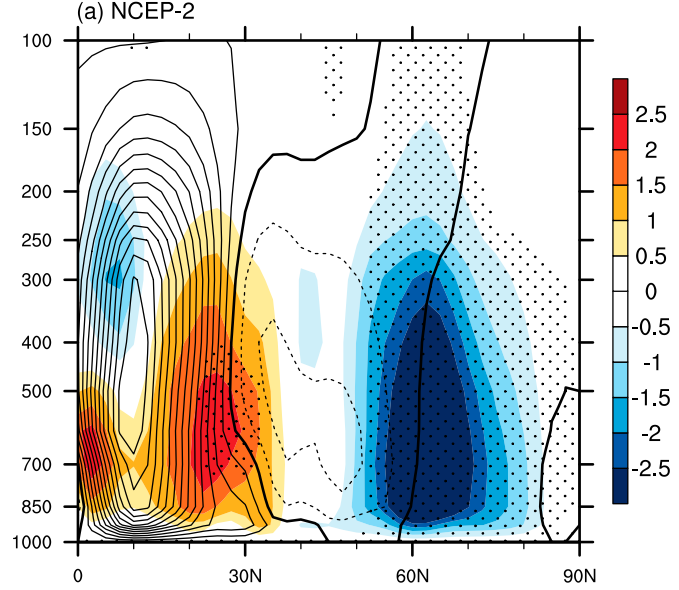

(b) ERA-Interim

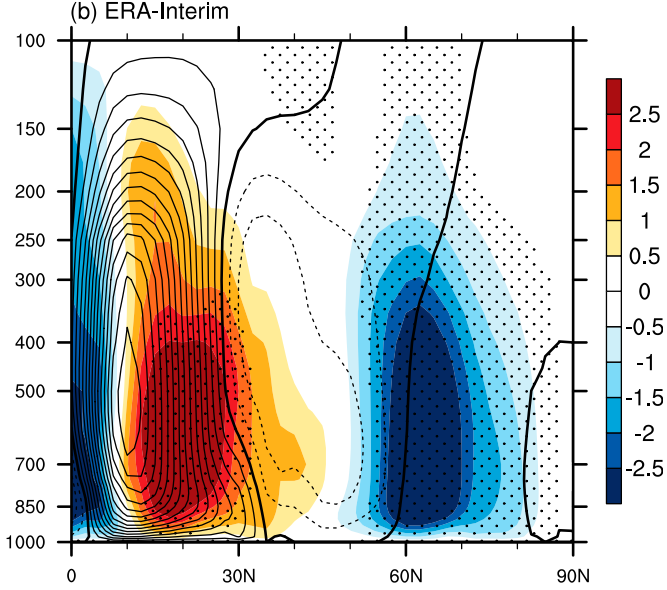

FIG. 2. Boreal spring climatological MSF (contours) and its anomalies (shading; units: $10^{9} \mathrm{~kg} \mathrm{~s}^{-1}$ ) regressed onto the spring AO index based on (a) NCEP-2 and (b) ERA-Interim. Contour intervals are $0.8 \times 10^{10} \mathrm{~kg} \mathrm{~s}^{-1}$. Stippled areas are statistically significant at/above the $95 \%$ confidence level. The thick solid lines indicate the zero values. 


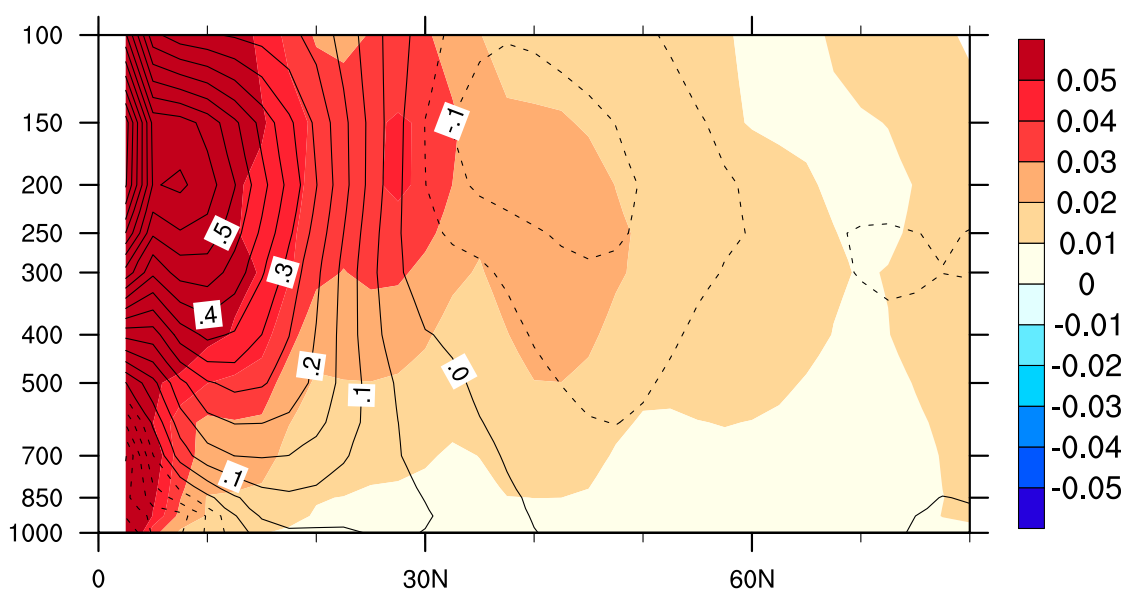

FIG. 3. Climatology (contours) and standard deviation (shading) of the boreal spring Ro based on the period 1979-2014.

one positive cell and two negative cells. The positive cell is located within $10^{\circ}-40^{\circ} \mathrm{N}$, while the two negative cells are in the deep tropics and midlatitudes $\left(40^{\circ}-70^{\circ} \mathrm{N}\right)$, respectively. The results from the two reanalysis datasets are similar. The positive cell crosses the boundary between the $\mathrm{HC}$ and the Ferrel cell, which tends to shift the HCE poleward. Note that the midlatitude negative cell crosses the boundary between the Ferrel and polar cells, which may cause a poleward displacement of the midlatitude storm track. But changes in the midlatitude Ferrel cell are beyond the scope of this study and are therefore not discussed here.

In the subtropics, the leading order of the zonal momentum budget can be approximately expressed as follows (Walker and Schneider 2006; Caballero 2007):

$$
[f+(\bar{\zeta})][\bar{v}]=(1-\operatorname{Ro}) f[\bar{v}] \approx[S],
$$

where $[\bar{\zeta}]=-\{\partial(\cos \varphi[\bar{u}]) / \partial \varphi\} / a \cos \varphi$ is the relative vorticity; Ro $=-[\bar{\zeta}] / f$ is the Rossby number; and $S=\left(1 / a \cos ^{2} \varphi\right)\left\{\partial\left(\cos ^{2} \varphi\left[u^{*} v^{*}\right]\right) / \partial \varphi\right\}$ is the horizontal eddy momentum flux divergence; the other parameters are the same as those in the above equations. The daily datasets were used to calculate the total $S$ for each day and then average the daily total $S$ to obtain the monthly total $S$. The stationary component of $S\left(S_{\mathrm{st}}\right)$ was calculated with the monthly mean data and the transient component of $S\left(S_{\mathrm{tr}}\right)$ was obtained by subtracting $S_{\mathrm{st}}$ from the monthly total $S$. We calculated the budgets of the AO related $f[\bar{v}],[\bar{\zeta}][\bar{v}]$, and $[S]$ based on Eq. (7) on interannual time scale. It turns out that $[S]$ is mainly balanced by $f[\bar{v}]$, while $[\bar{\zeta}][\bar{v}]$ is much smaller than $f[\bar{v}]$ and $[S]$ (figure not shown). That means that Eq. (7) can be held on interannual time scale associated with AO. In the extratropics, Ro is small, which is close to the limit of
Ro $\rightarrow 0$, and its interannual variability is much smaller (Fig. 3). Thus, $\bar{v} \approx(S / f)$. As the HC is an integration of $\bar{v}$, the latitude of $\bar{v}=0$ is also a proxy of the HCE. Therefore, the $\mathrm{HCE}$ can be directly influenced by $S$, given $\bar{v} \approx(S / f)$ (e.g., Schneider 2006; Walker and Schneider 2006; Caballero 2007).

According to the above theory, the meridional wind changes associated with the eddy momentum divergence were analyzed. Figure 4 shows that the AO index regressed meridional wind and those converted from $S_{\text {st }}$ and $S_{\text {tr }}$ based on Eq. (7) $\{v \approx[S /(1-$ Ro $) f]\}$. The climatological meridional wind and those converted from $S_{\mathrm{st}}$ and $S_{\mathrm{tr}}$ show positive values in the tropical upper troposphere (around $200 \mathrm{hPa}$ ) and negative values in the midlatitude upper troposphere (around $200 \mathrm{hPa}$ ). It is clear that there are positive meridional wind anomalies in the subtropics (around $30^{\circ} \mathrm{N}$ ), and negative anomalies in midlatitudes (around $60^{\circ} \mathrm{N}$ for $S_{\text {st }}$ and $70^{\circ} \mathrm{N}$ for $S_{\text {tr }}$ ), both of which are located in the mid- to upper troposphere $(500-200 \mathrm{hPa})$. The positive meridional wind anomalies are over the subtropical region where the HCE is located. The meridional wind anomalies associated with $S_{\text {st }}$ and $S_{\text {tr }}$ show similar patterns to that of the $\mathrm{AO}$, which also has a magnitude comparable to that of the sum of meridional wind anomalies associated with the $S_{\mathrm{st}}$ and $S_{\mathrm{tr}}$. However, $S_{\text {tr }}$ makes nearly 2 times larger contributions than the $S_{\text {st }}$ to the change in meridional wind anomalies over the subtropical upper troposphere near $30^{\circ} \mathrm{N}$ (Figs. 4b,c). That means that changes in the AO-associated eddy momentum flux divergence are responsible for the increased southerly wind (or a poleward shift of the HCE), and the transient component of the eddy momentum flux makes a larger contribution than that of the stationary component. 

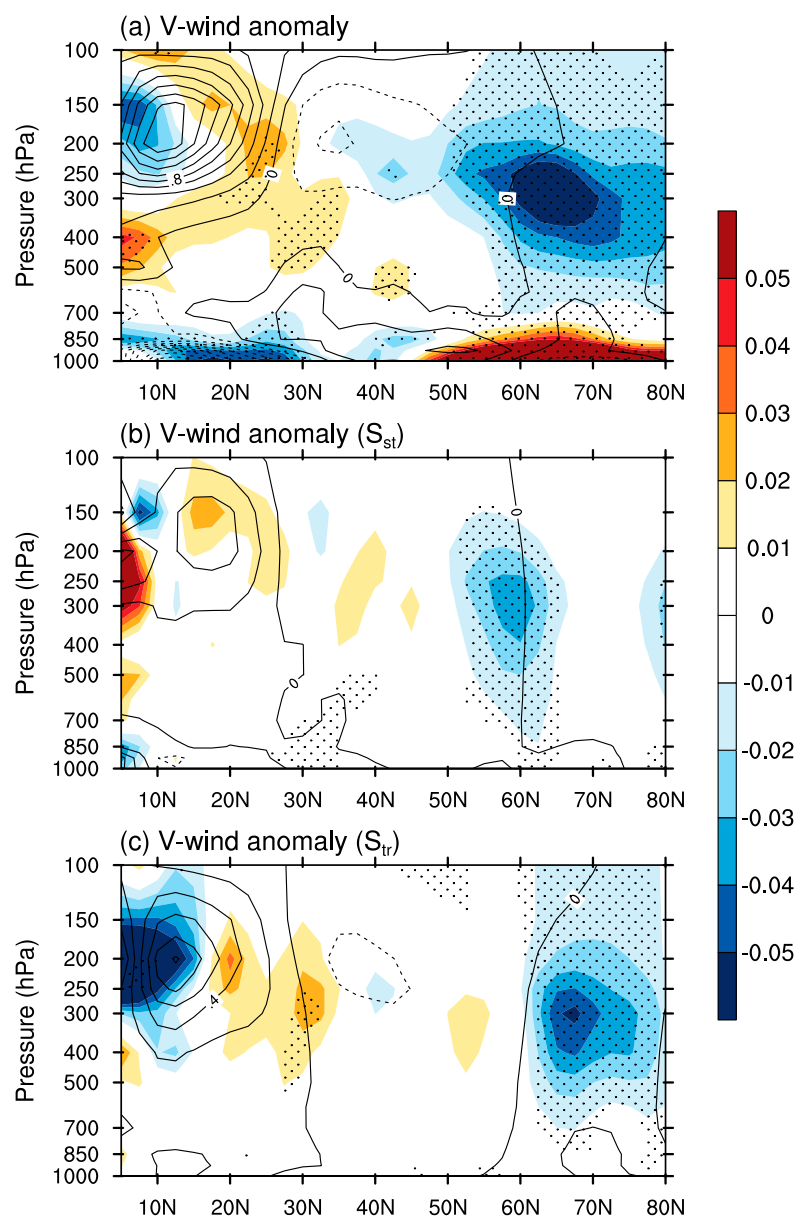

FIG. 4. (a) The climatological MAM mean meridional wind (contours; units: $\mathrm{m} \mathrm{s}^{-1}$ ) and its anomalies (shading; units: $\mathrm{m} \mathrm{s}^{-1}$ ) regressed onto the spring AO index during the period 19792014. (b) As in (a), but meridional wind is converted from $S_{\mathrm{st}}\{v \approx$ $\left.\left[S_{\mathrm{st}} /(1-\mathrm{Ro}) f\right]\right\}$. (c) As in (b), but converted from $S_{\mathrm{tr}}$.

\section{b. Planetary wave activity connecting AO to $H C E$}

A question arises as to how the AO connects to the anomalous eddy momentum flux divergence over the subtropical troposphere. Because the eddy momentum flux divergence $S=\left(1 / a \cos ^{2} \varphi\right)\left\{\partial\left(\cos ^{2} \varphi\left[u^{*} v^{*}\right]\right) / \partial \varphi\right\}$ is in proportion to meridional component of the EP flux divergence $(\partial / \partial \varphi) F_{\varphi}=-(1 / \cos \varphi)\left\{\partial\left(\cos ^{2} \varphi\left[u^{*} v^{*}\right]\right) / \partial \varphi\right\}$ but with opposite sign (i.e., the convergence of EP flux corresponds to the divergence of the eddy momentum flux), we further show the AO-related stationary and transient EP fluxes and their divergence (Fig. 5). An enhanced wave propagation from the midlatitudes to the tropics along with a convergence of the EP flux in the subtropical upper troposphere is observed (Figs. 5a,b), which agrees well with Thompson et al. (2003). As the divergence of the EP flux represents the eddy momentum forcing on mean flow, a convergence of the EP flux implies the zonal easterly forcing induced by waves on mean flow (Andrew et al. 1987) that decelerates a westerly zonal mean flow, we can see that there is an anomalous convergence of the EP flux over the subtropics (Figs. 5a,b), corresponding to a slowdown of the subtropical jet (Fig. 5e). That means the anomalous convergence of EP flux over the subtropical troposphere related to AO could induce strengthened easterly momentum forcing on mean flow there. The convergence area of the EP flux located in the extratropical troposphere is mainly controlled by the equatorward branch of EP flux vectors (i.e., the eddy momentum flux in the subtropical higher troposphere) (Andrews et al. 1987), which can also be seen in the climatological mean of meridional components of EP flux divergence in Figs. 5c and $5 \mathrm{~d}$. Thus, the anomalous convergence in the EP flux related to AO corresponds to an anomalous divergence in the eddy momentum flux in the subtropical troposphere.

Previous studies discussed that the EP fluxes are closely related to RI (Palmer 1981, 1982; Karoly and Hoskins 1982; Butchart et al. 1982; Andrews et al. 1987; Chen and Robinson 1992; Hu et al. 2015, 2019; Hu and Guan 2018). They showed that the regions with larger EP flux vectors always correspond to larger RI and the trajectories of the EP flux vectors are refracted up the gradient of RI. The EP flux and RI can provide a useful way of visualizing the propagation pattern of planetary waves in the latitude-height plane. To further understand the propagation of stationary and transient waves, Fig. 6 shows the anomalies in the stationary wave RI and transient wave RI for zonal wavenumber 3 regressed on the normalized AO index during 1979-2014 in MAM. The reason we chose wavenumber 3 is that the wave train shown in Fig. 7 below exhibits a wavenumber-3 pattern. We can see that the stationary wave RI increases at subtropics but decreases at higher latitudes (Fig. 6a). Because waves always tend to propagate into the large RI value areas (Andrews et al. 1987; Chen and Robinson 1992), such anomalous stationary wave RI pattern tends to induce anomalous equatorward wave propagation over the subtropics, consistent with the EP flux anomalies. As the basic state of the zonal mean winds is usually represented by $10 \mathrm{~m} \mathrm{~s}^{-1}$, the traveling wave RI with a value of $10 \mathrm{~m} \mathrm{~s}^{-1}$ phase speed is chosen for an example following $\mathrm{Hu}$ et al. (2015). The pattern of the westward-traveling wave RI in response to the positive AO phases (Fig. 6b) is similar to that of stationary wave RI, suggesting the equatorward propagation of westward-traveling waves also enhances during the positive AO phases. This can explain why the transient EP flux also has equatorward propagation anomalies, similar to the stationary EP flux anomalies. 
(a) Stationary

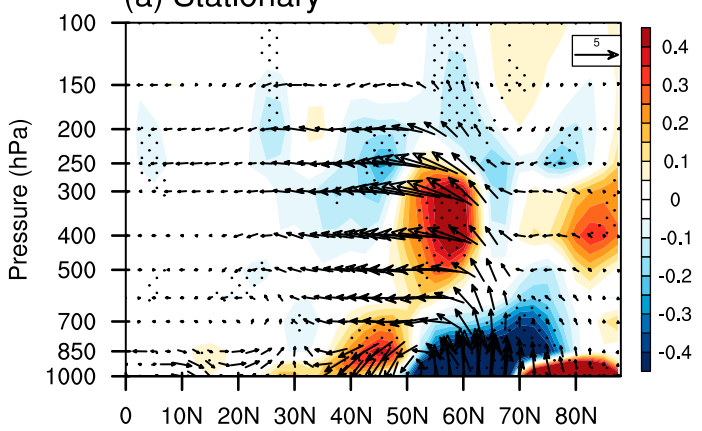

(c) Stationary

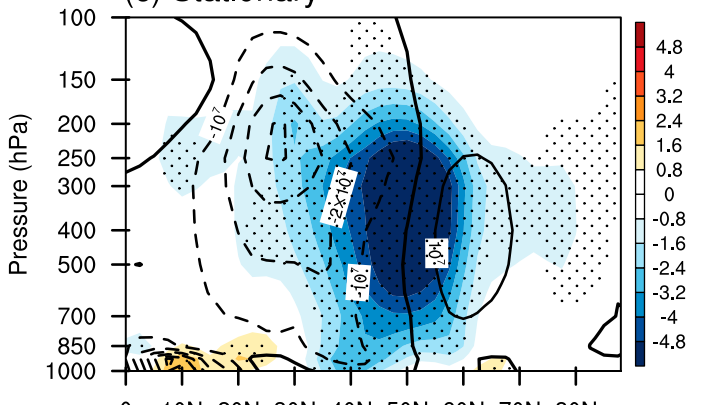

(b) Transient

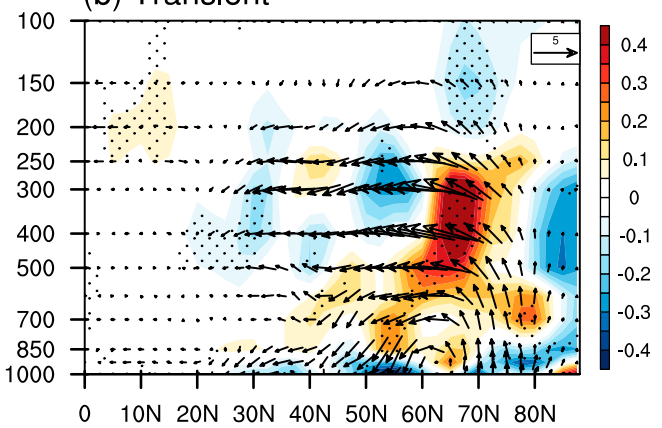

(d) Transient

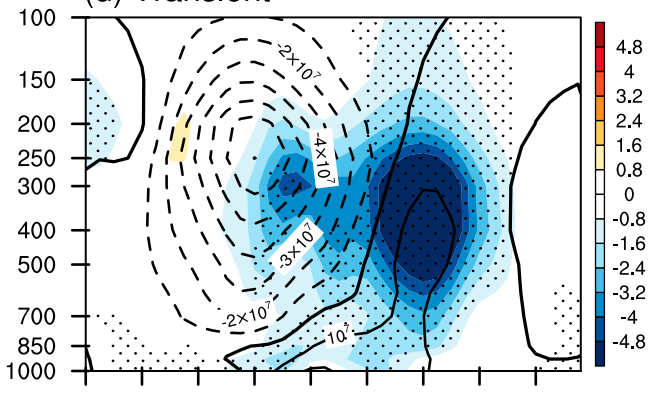

$0 \quad 10 \mathrm{~N} 20 \mathrm{~N} 30 \mathrm{~N} 40 \mathrm{~N} 50 \mathrm{~N} 60 \mathrm{~N} 70 \mathrm{~N} 80 \mathrm{~N}$

(e) U

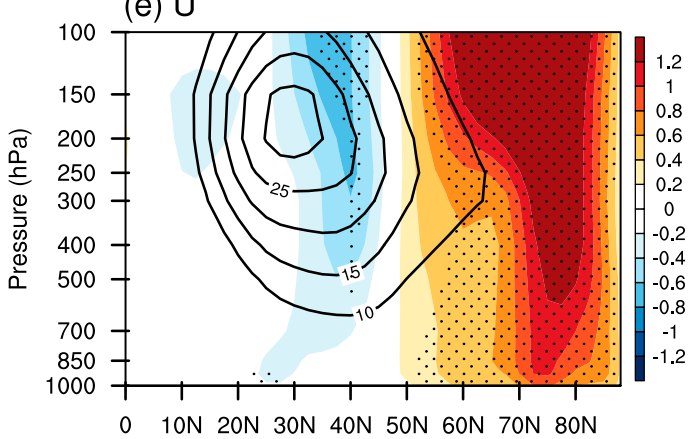

FIG. 5. Anomalies in the (a) stationary and (b) transient components of the EP flux (vectors; units for horizontal and vertical vectors are $10^{6}$ and $10^{4} \mathrm{~kg} \mathrm{~s}^{-2}$, respectively) and their divergences (shading; units: $\mathrm{m} \mathrm{s}^{-2}$ ) regressed upon the normalized AO index during 1979-2014 in MAM. Climatology (contours; units: $10^{6} \mathrm{~kg} \mathrm{~s}^{-2}$ ) and anomalies (shading; units: $10^{6} \mathrm{~kg} \mathrm{~s}^{-2}$ ) in the meridional components of (c) stationary and (d) transient EP flux divergences regressed upon the normalized AO index during 1979-2014 in MAM. (e) Climatology (contours; units: $\mathrm{m} \mathrm{s}^{-1}$ ) and anomalies (shading; units: $\mathrm{m} \mathrm{s}^{-1}$ ) in the zonal wind regressed upon the normalized AO index. Stippled areas are statistically significant at/above the $95 \%$ confidence level.

Additionally, the anomalies in the eastward-traveling wave RI related to AO (Fig. 6c) exhibit larger meridional gradient than that of the stationary wave RI (Fig. 6a), which may explain why the AO-related HCE expansion is mainly induced by transient eddy momentum flux divergence. And the anomalies in the eastward-traveling wave RI are also larger than those in westward-traveling wave RI, which suggests that the increased equatorward transient wave flux over the subtropics is possibly related to the anomalies in the refraction of eastward-traveling waves.
To give more details about the regional aspects of the equatorward wave propagation, Fig. 7 further shows 300-hPa horizontal wave flux, geopotential height, streamfunction, and the horizontal wind anomalies regressed on the normalized AO index. The zonal mean of the geopotential height is removed in order to capture the stationary wave component associated with AO. There are wave train patterns originating from the midto high latitudes of North Atlantic and propagating to the tropical North Atlantic and North Africa, respectively. Similar results are also observed in the lower 
(a) Stationary

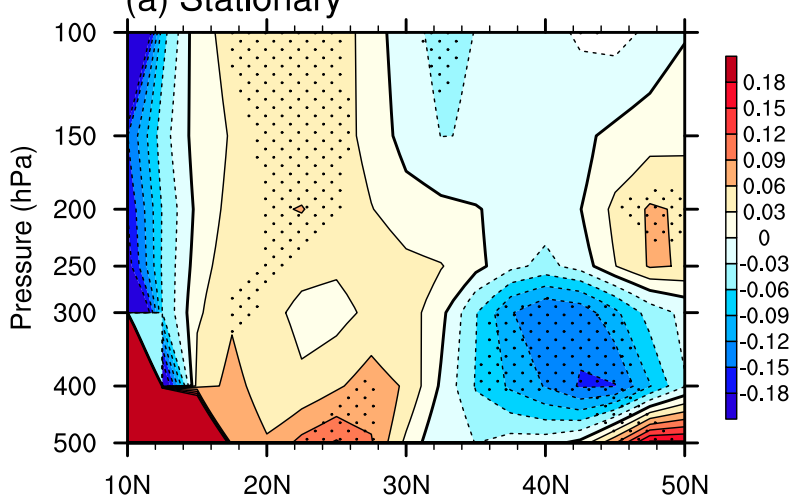

(b) Westward Transient

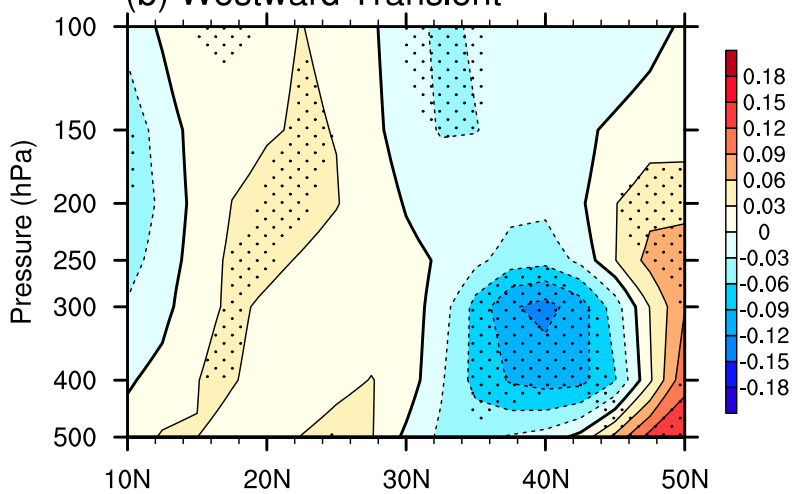

(c) Eastward Transient

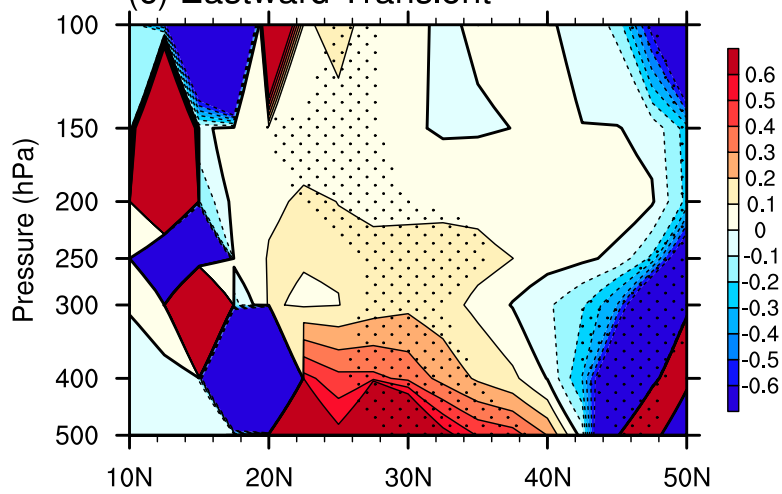

FIG. 6. The RI (units: $10^{-12} \mathrm{~m}^{-2}$ ) anomalies for zonal wavenumber-3 (a) stationary waves, (b) westward-traveling waves, and (c) eastward-traveling waves with a phase speed $10 \mathrm{~m} \mathrm{~s}^{-1}$ regressed on the normalized AO index during 1979-2014 in MAM. Stippled areas are statistically significant at/above the $90 \%$ confidence level.

troposphere (figure not shown), indicating an equivalent barotropic structure of the wave train patterns. These wave train patterns play important roles in forcing the AO zonal anomalies (e.g., Kimoto et al. 2001) and the one propagating to the tropical North Atlantic resembles the North Atlantic Oscillation (NAO) pattern. The AO index is also highly correlated with the NAO index $(r=0.71, p<0.05)$. These results indicate that the NAO is an important manifestation of the AO over the Atlantic sector and they share common features in their associated wave train patterns (e.g., Thompson and Wallace 1998; Ambaum et al. 2001; Thompson et al. 2003; Lorenz and Hartmann 2003; Vallis et al. 2004; Son and Lee 2005). Thus, it can be seen that the AO-related equatorward wave propagation is mainly contributed by the Atlantic sector, consistent with previous studies (e.g., Thompson and Wallace 1998; Ambaum et al. 2001; Thompson et al. 2003; Son and Lee 2005), which means the equatorward wave propagation over the Atlantic sector plays an important role in shifting the HCE poleward during the AO positive phase.

\section{Seasonal differences in the AO-HCE relationship}

The spring AO can impact the tropical climate such as East Asian monsoon system and ENSO events in the following seasons (Nakamura et al. 2006; Gong et al. 2011; Chen et al. 2005, 2014a). Whether HCE has a lagged relationship with $\mathrm{AO}$ is still unknown. By correlating the $\mathrm{AO}$ index in each season to the $\mathrm{HCE}$ with a one-season lag, it is found that none of the four seasons shows a significant AO-HCE relationship. Comparatively, the simultaneous correlations between $\mathrm{AO}$ and HCE are significant during autumn $(r=0.63)$ and winter $(r=0.43)$ and insignificant during summer $(r=0.16)$. Unlike the AO-ENSO relationship, the AO-HCE has no lagged relationship, possibly because the propagation of the tropospheric planetary waves is much faster than the slow air-sea interaction processes (e.g., Nakamura et al. 2006; Gong et al. 2011; Chen et al. 2014a).

To understand the seasonal difference of the AOHCE relationships, Fig. 8 further shows the AO associated EP flux in summer, autumn, and winter. All the three seasons show an equatorward wave propagation similar to that in spring (Figs. 5a,b), but with relatively smaller magnitudes in summer and autumn. For the summer and autumn, the equatorward stationary and transient wave flux anomalies have comparable magnitudes, whereas for winter the transient component is much smaller than the stationary component. For the horizontal wave propagation, the NAO-like pattern is observed over the Atlantic sector in summer and winter (Figs. 9a,c). Autumn has weak wave propagation to the tropical Atlantic but has obvious wave propagation to central Asia (Fig. 9b). As a result, the three seasons show similar spatial structures of MSF anomalies to that in spring (Figs. 2 and 10). However, the summer climatological HCE is farther poleward extended than the other three seasons, when the 
(a) Z \& wave flux

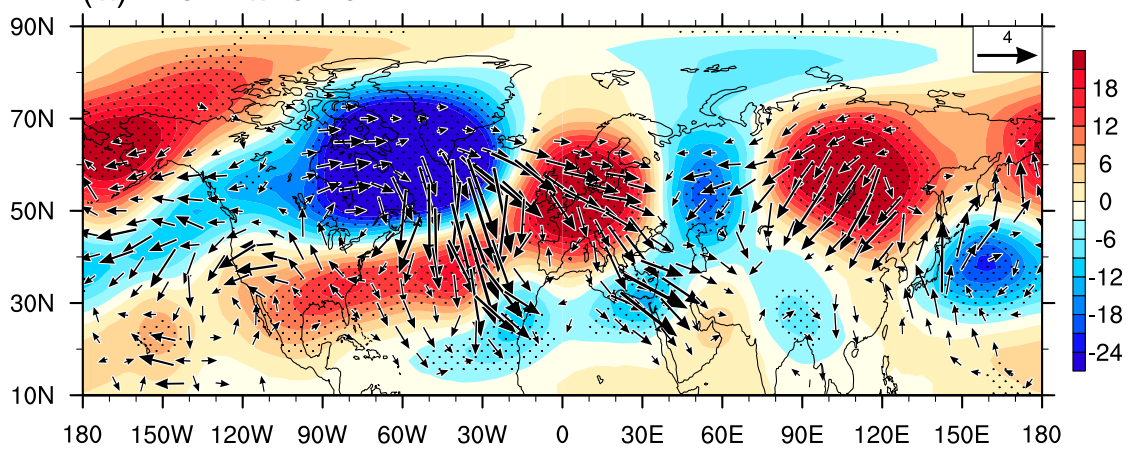

(b) Stream function \& winds

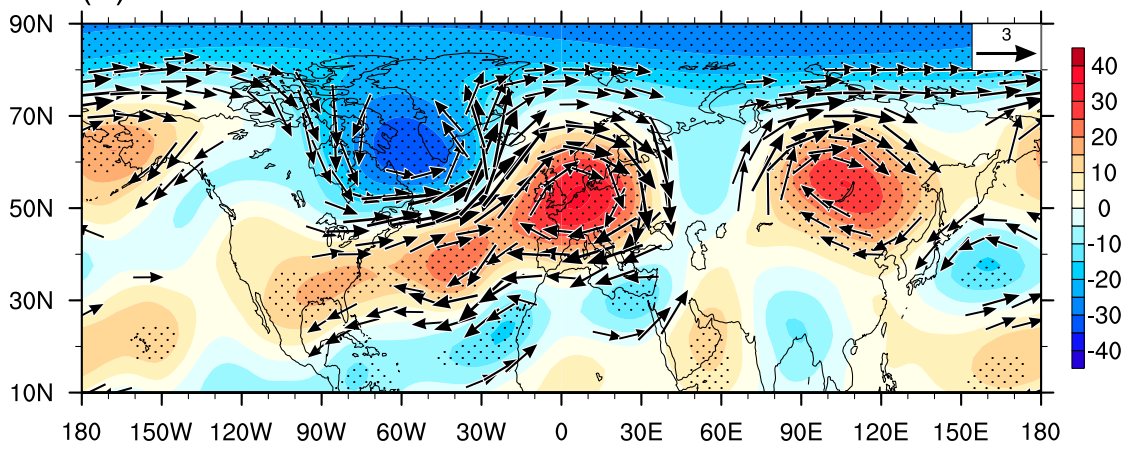

FIG. 7. Anomalies of the $300-\mathrm{hPa}$ (a) geopotential height (shading; units: $\mathrm{m}$ ) and the horizontal stationary wave activity flux (vectors; units: $\mathrm{m}^{2} \mathrm{~s}^{-2}$; only the vectors above $0.6 \mathrm{~m}^{2} \mathrm{~s}^{-2}$ are shown) regressed onto the AO index during 1979-2014 in MAM. (b) Anomalies of the streamfunction (shading; units: $10^{5} \mathrm{~m}^{2} \mathrm{~s}^{-1}$ ) and horizontal winds (vectors; only the vectors above $1.5 \mathrm{~m} \mathrm{~s}^{-1}$ are shown) regressed onto the AO index. Stippled areas are statistically significant at or above the $95 \%$ confidence level.

climatological HCEs are located within the MSF anomalies related to the AO. Thus, the climatologically poleward extended HCE is possibly the cause for the weak statistical relationship between the AO index and the HCE in summer.

\section{Conclusions and discussion}

This study investigates the statistical relationship and dynamical linkages between the spring $\mathrm{AO}$ and the HCE in the NH. It is found that the positive (negative) AO phases correspond to a poleward (equatorward) shift of the HCE in the NH. Quantitatively, one positive standard deviation's increase of the AO index corresponds to an approximate $0.42^{\circ}$ latitude poleward shift of the HCE. The relationship between the AO and the $\mathrm{HCE}$ are tightly connected to the eddy momentum flux divergence in the subtropical mid- to upper troposphere. The transient component of the eddy momentum flux divergence makes a relatively larger contribution to the changes in HCE than that of the stationary component. The increased equatorward transient wave flux over the subtropics is possibly related to the anomalies in the refraction of eastward-traveling waves. Further analysis revealed that the increased eddy momentum flux divergence is related to an enhanced wave propagation from the mid- to high latitudes to the lower latitudes within the Atlantic sector, which is like the NAO pattern.

Previous studies pointed out that the AO fluctuation is associated with zonal momentum flux of baroclinic waves across the midlatitudes, and its largest variance is located over the Atlantic sector (e.g., Thompson et al. 2003). The AO manifests most strongly in the Atlantic sector (Thompson and Wallace 1998; Ambaum et al. 2001; Thompson et al. 2003) because of the relatively weak thermal-driven subtropical flow and warmer boundary conditions at mid- to high latitudes, which allows a significant southward extension of baroclinic waves (Thompson et al. 2003). There have been studies suggesting that the interannual fluctuation of the AO is significantly correlated with that of the HCE (e.g., Nakamura et al. 2006; Nguyen et al. 2013; Guo and Li 2016), and Thompson et al. (2003) also showed the 


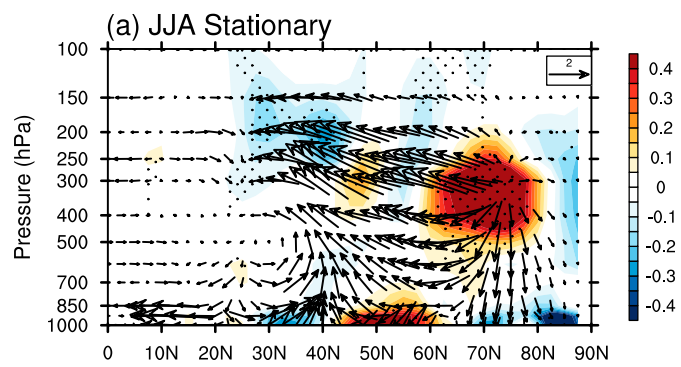

(b) SON Stationary

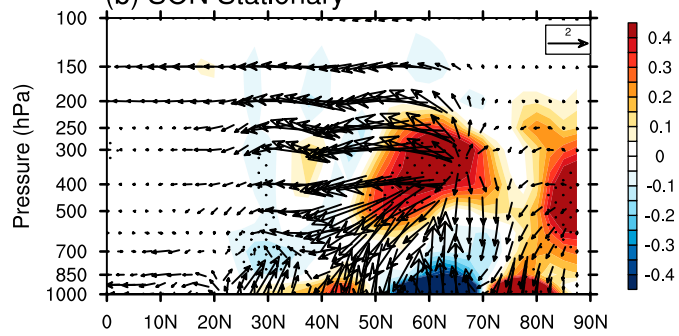

(c) DJF Stationary

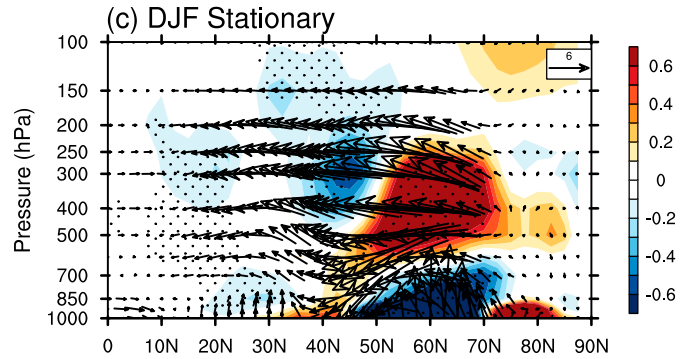

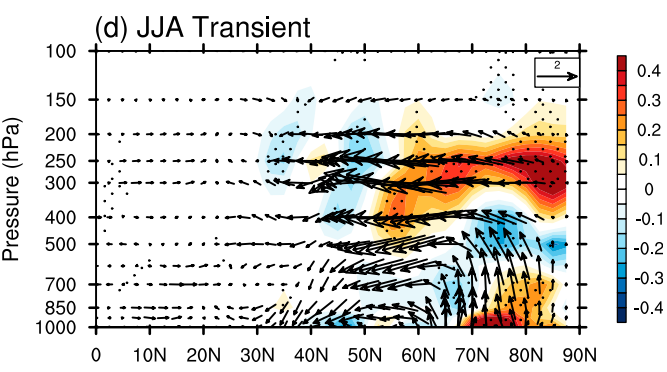

(e) SON Transient
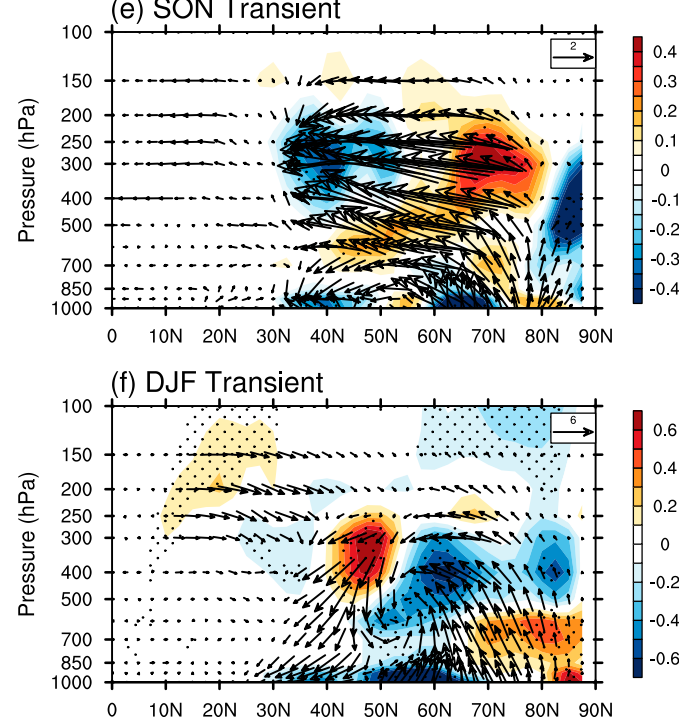

FIG. 8. The stationary component of the anomalous EP flux (vectors; units for horizontal and vertical vectors are $10^{6}$ and $10^{4} \mathrm{~kg} \mathrm{~s}^{-2}$, respectively) and its divergence (shading; units: $\mathrm{m} \mathrm{s}^{-2}$ ) regressed onto the AO index during 1979-2014 in (a) JJA, (b) SON, and (c) DJF. (d)-(f) As in (a)-(c), but for the transient component. Stippled areas are statistically significant at or above the $95 \%$ confidence level.

meridional circulation change associated with the $\mathrm{AO}$ variation during late winter season. We suggest that the dynamical process linking the AO and the HCE is the strengthened equatorward wave propagation, which is the strongest over the North Atlantic sector. This is consistent with previous studies (e.g., Thompson and Wallace 1998; Ambaum et al. 2001; Thompson et al. 2003; Son and Lee 2005). We further pointed out that the transient wave flux makes nearly 2 times larger contributions to the HCE interannual variability than that of the stationary wave flux (Figs. 4b,c). Further analysis indicates that autumn and winter have a similar AO-HCE relationship. However, such a relationship in summer is statistically insignificant, which is possibly related to the climatological position of the northern cell in summer (Fig. 10a) and the relatively weaker wave activity (Figs. 8a,d).

Previous studies suggested that the spring AO can impact the subsequent winter ENSO events via wave-mean flow interaction over the North Pacific and associated vorticity transportation (Chen et al. 2014a, 2017). This relationship experienced an interdecadal shift during the 1970s because of the stronger synoptic-scale eddy feedback to the lowfrequency flow after 1970 (Chen et al. 2015). Our results show that the HCE is linked to the AO in the same season via the equatorward propagation of the planetary wave over the Atlantic region (Fig. 7a), which is in a different ocean basin. Whether the circulation change in the subtropical Atlantic can affect the tropical Pacific SST is worth further investigation. Additionally, it was suggested that the regional $\mathrm{HC}$ can have a significant impact on the regional climate (e.g., Chen et al. 2014b; Huang et al. 2017; Guo and Tan 2018). Whether the HCE is actually important for subtropical precipitation over land is the subject of debate (e.g., Schmidt and Grise 2017). As the spring AO has a significant impact on the tropical SST and precipitation during the following summer and winter (e.g., Nakamura et al. 2006; Chen 
(a) JJA

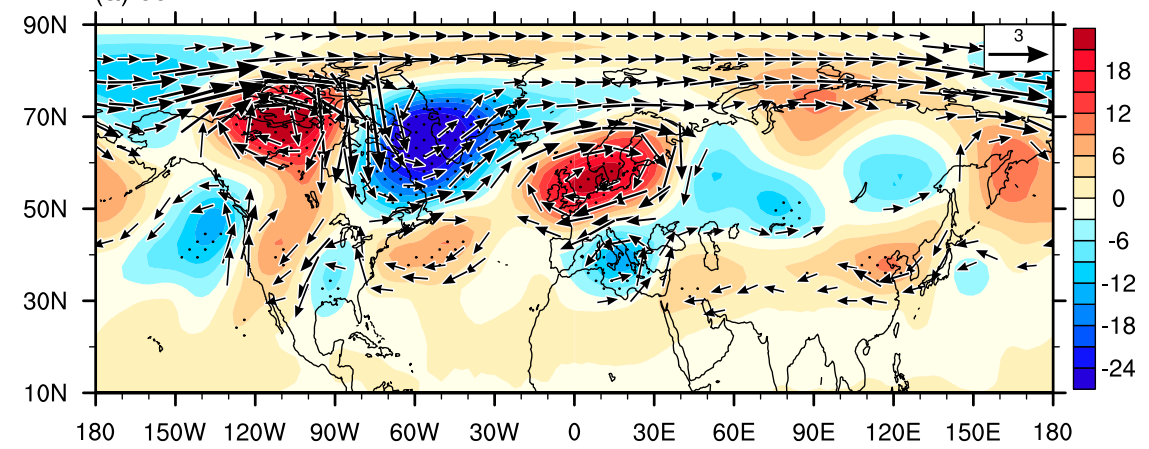

(b) SON

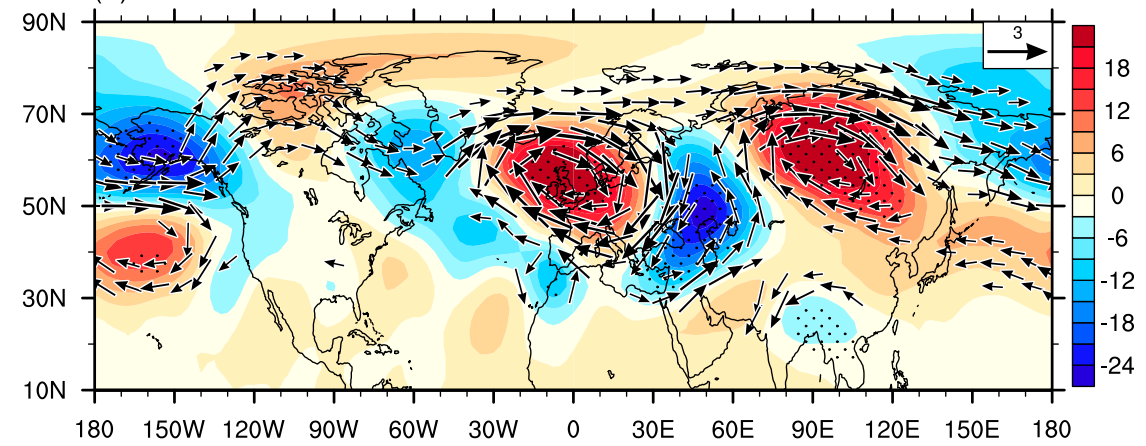

(c) DJF

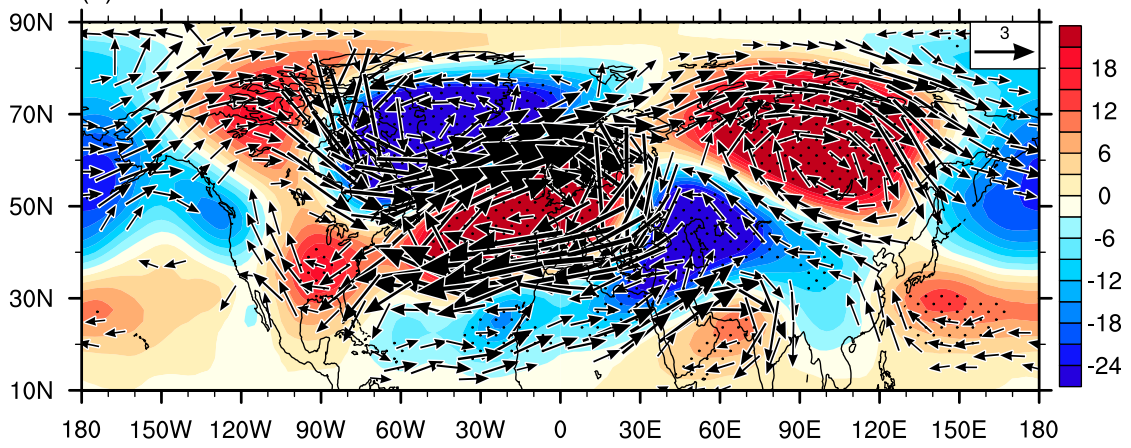

FIG. 9. Regression of the zonal deviation of 300-hPa geopotential height (shading; units: $\mathrm{m}$ ) and horizontal winds (vectors; only the vectors above $1 \mathrm{~m} \mathrm{~s}^{-1}$ are shown) onto the AO index during (a) summer, (b) autumn, and (c) winter. Stippled areas are statistically significant at/above the $95 \%$ confidence level.

et al. 2014a, 2015, 2017), it is possible that the spring AO may also have an impact on the regional HCE during the following summer or winter, although their statistical relationships are insignificant from a zonal mean perspective. But this needs further investigation in the future.

Acknowledgments. We thank three anonymous reviewers and the editor for providing useful comments. We are grateful to the groups and agencies for providing the datasets used in this study. The NCEP2 data can be accessed from http://www.esrl.noaa.gov/psd/ data/gridded/data.ncep.reanalysis2.pressure.html. The
ECMWF data were obtained from the European Centre for Medium-Range Weather Forecasts (available online at https://apps.ecmwf.int/datasets/data/ interim-full-daily/levtype $=\mathrm{sfc} /$ ). This work is jointly supported by the National Natural Science Foundation of China (41805031, 41705057), the National Key Research and Development Program of China under Grant 2017YFC1501601, the Natural Science Foundation of Jiangsu Province (BK20160949, BK20170637), the China Postdoctoral Science Foundation funded project (2018M632282), and the Startup Foundation for Introducing Talent of NUIST (2017r040). 

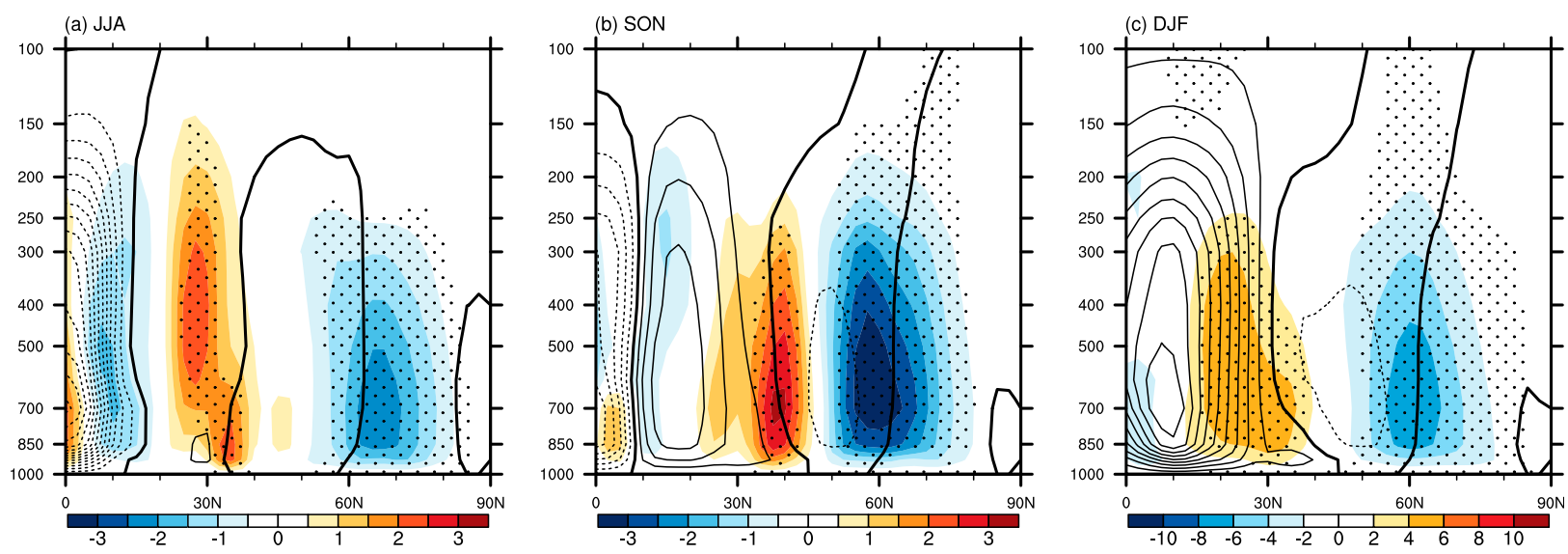

FIG. 10. As in Fig. 2a, but for (a) summer, (b) autumn, and (c) winter.

\section{REFERENCES}

Adam, O., T. Schneider, and N. Harnik, 2014: Role of changes in mean temperatures versus temperature gradients in the recent widening of the Hadley circulation. J. Climate, 27, 7450-7461, https://doi.org/10.1175/JCLI-D-14-00140.1.

Allen, R. J., S. C. Sherwood, J. R. Norris, and C. S. Zender, 2012: Recent Northern Hemisphere tropical expansion primarily driven by black carbon and tropospheric ozone. Nature, $\mathbf{4 8 5}$, 350-354, https://doi.org/10.1038/nature11097.

_ J. R. Norris, and M. Kovilakam, 2014: Influence of anthropogenic aerosols and the Pacific Decadal Oscillation on tropical belt width. Nat. Geosci., 7, 270-274, https://doi.org/ 10.1038/ngeo2091.

Ambaum, M. H., B. J. Hoskins, and D. B. Stephenson, 2001: Arctic Oscillation or North Atlantic Oscillation? J. Climate, 14, 3495-3507, https://doi.org/10.1175/1520-0442(2001)014<3495: $\mathrm{AOONAO}>2.0 . \mathrm{CO} ; 2$.

Andrews, D. G., J. R. Holton, and C. B. Leovy, 1987: Middle Atmosphere Dynamics. Academic Press, 489 pp.

Bony, S., G. Bellon, D. Klocke, S. Sherwood, S. Fermepin, and S. Denvil, 2013: Robust direct effect of carbon dioxide on tropical circulation and regional precipitation. Nat. Geosci., 6, 447-451, https://doi.org/10.1038/ngeo1799.

Butchart, N., S. A. Clough, T. N. Palmer, and P. J. Trevelyan, 1982: Simulations of an observed stratospheric warming with quasigeostrophic refractive index as a model diagnostic. Quart. J. Roy. Meteor. Soc., 108, 475-502, https://doi.org/10.1002/ qj. 49710845702 .

Caballero, R., 2007: Role of eddies in the interannual variability of Hadley cell strength. Geophys. Res. Lett., 34, L22705, https:// doi.org/10.1029/2007GL030971.

Ceppi, P., and D. L. Hartmann, 2013: On the speed of the eddydriven jet and the width of the Hadley cell in the Southern Hemisphere. J. Climate, 26, 3450-3465, https://doi.org/ 10.1175/JCLI-D-12-00414.1.

Chen, P., and W. A. Robinson, 1992: Propagation of planetary waves between the troposphere and stratosphere. J. Atmos. Sci., 49, 2533-2545, https://doi.org/10.1175/1520-0469(1992) 049<2533:POPWBT>2.0.CO;2.

Chen, S., B. Yu, and W. Chen, 2014a: An analysis on the physical process of the influence of AO on ENSO. Climate Dyn., 42, 973-989, https://doi.org/10.1007/s00382-012-1654-z.
— , K. Wei, W. Chen, and L. Y. Song, 2014b: Regional changes in the annual mean Hadley circulation in recent decades. J. Geophys. Res. Atmos., 119, 7815-7832, https://doi.org/ 10.1002/2014JD021540.

- B. Yu, and W. Chen, 2015: An interdecadal change in the influence of the spring Arctic Oscillation on the subsequent ENSO around the early 1970s. Climate Dyn., 44, 1109-1126, https://doi.org/10.1007/s00382-014-2152-2.

- W. Chen, and B. Yu, 2017: The influence of boreal spring Arctic Oscillation on the subsequent winter ENSO in CMIP5 models. Climate Dyn., 48, 2949-2965, https://doi.org/10.1007/ s00382-016-3243-z.

Chen, W., S. Yang, and R.-H. Huang, 2005: Relationship between stationary planetary wave activity and the East Asian winter monsoon. J. Geophys. Res., 110, D14110, https://doi.org/ 10.1029/2004JD005669.

Dee, D. P., and Coauthors, 2011: The ERA-Interim reanalysis: Configuration and performance of the data assimilation system. Quart. J. Roy. Meteor. Soc., 137, 553-597, https://doi.org/ 10.1002/qj.828.

Duchon, C., 1979: Lanczos filtering in one and two dimensions. J. Appl. Meteor., 18, 1016-1022, https://doi.org/10.1175/15200450(1979)018<1016:LFIOAT>2.0.CO;2.

Edmon, H. J., B. J. Hoskins, and M. E. McIntyre, 1980: EliassenPalm cross sections for the troposphere. J. Atmos. Sci., 37, 2600-2616, https://doi.org/10.1175/1520-0469(1980)037<2600: EPCSFT $>2.0 . \mathrm{CO} ; 2$.

Fu, Q., C. M. Johanson, J. M. Wallace, and T. Reichler, 2006: Enhanced mid-latitude tropospheric warming in satellite measurements. Science, 312, 1179, https://doi.org/10.1126/ science. 1125566 .

Garfinkel, C. I., D. W. Waugh, and L. M. Polvani, 2015: Recent Hadley cell expansion: The role of internal atmospheric variability in reconciling modeled and observed trends. Geophys. Res. Lett., 42, $10824-10831$, https://doi.org/ 10.1002/2015GL066942.

Glickman, T., Ed., 2000: Glossary of Meteorology. 2nd ed. Amer. Meteor. Soc., 855 pp., http://glossary.ametsoc.org/.

Gong, D.-Y., J. Yang, S.-J. Kim, Y. Q. Gao, D. Guo, T. J. Zhou, and M. Hu, 2011: Spring Arctic Oscillation-East Asian summer monsoon connection through circulation changes over the western North Pacific. Climate Dyn., 37, 2199-2216, https:// doi.org/10.1007/s00382-011-1041-1. 
Guo, Y.-P., and J.-P. Li, 2016: Impact of ENSO events on the interannual variability of Hadley circulation extents in boreal winter. Adv. Climate Change Res., 7, 46-53, https://doi.org/ 10.1016/j.accre.2016.05.001.

, and Z. M. Tan, 2018: Impacts of the boreal spring Indo-Pacific warm pool Hadley circulation on tropical cyclone activity over the western North Pacific. J. Climate, 31, 1361-1375, https:// doi.org/10.1175/JCLI-D-17-0422.1.

Hadley, G., 1735: Concerning the cause of the general trade-winds. Philos. Trans. Roy. Soc. London, 29, 58-62., https://doi.org/ 10.1098/rstl.1735.0014.

Held, I. M., and A. Y. Hou, 1980: Nonlinear axially symmetric circulations in a nearly inviscid atmosphere. J. Atmos. Sci., 37, 515-533, https://doi.org/10.1175/1520-0469(1980)037<0515: NASCIA $>2.0 . \mathrm{CO} ; 2$.

Holton J. R., 1994: An Introduction to Dynamic Meteorology. Academic Press, 511 pp.

Hu, D., and Z. Guan, 2018: Decadal relationship between the stratospheric Arctic vortex and Pacific decadal oscillation. J. Climate, 31, 3371-3386, https://doi.org/10.1175/JCLI-D-17-0266.1.

— W. Tian, F. Xie, C. Wang, and J. Zhang, 2015: Impacts of stratospheric ozone depletion and recovery on wave propagation in the boreal winter stratosphere. J. Geophys. Res. Atmos., 120, 8299-8317, https://doi.org/10.1002/2014JD022855.

_- Y. Guo, and Z. Guan, 2019: Recent weakening in the stratospheric planetary wave intensity in early winter. Geophys. Res. Lett., 46, 3953-3962, https://doi.org/10.1029/2019GL082113.

$\mathrm{Hu}$, Y. Y., and Q. Fu, 2007: Observed poleward expansion of the Hadley circulation since 1979. Atmos. Chem. Phys., 7, 5229 5236, https://doi.org/10.5194/acp-7-5229-2007.

Huang, R. P., S. F. Chen, W. Chen, and P. Hu, 2017: Interannual variability of regional Hadley circulation intensity over western Pacific during boreal winter and its climatic impact over Asia-Australia region. J. Geophys. Res. Atmos., 123, 344-366, https://doi.org/10.1002/2017JD027919.

Johanson, C. M., and Q. Fu, 2009: Hadley cell widening: Model simulations versus observations. J. Climate, 22, 2713-2725, https://doi.org/10.1175/2008JCLI2620.1.

Kanamitsu, M., W. Ebisuzaki, J. Woollen, S.-K. Yang, J. J. Hnilo, M. Fiorino, and G. L. Potter, 2002: NCEP-DOE AMIP-II Reanalysis (R-2). Bull. Amer. Meteor. Soc., 83, 1631-1643, https://doi.org/10.1175/BAMS-83-11-1631.

Kang, S. M., L. M. Polvani, J. C. Fyfe, and M. Sigmond, 2011: Impact of polar ozone depletion on subtropical precipitation. Science, 332, 951-954, https://doi.org/10.1126/science.1202131.

Karoly, D. J., and B. J. Hoskins, 1982: Three dimensional propagation of planetary waves. J. Meteor. Soc. Japan, 60, 109-123, https://doi.org/10.2151/jmsj1965.60.1_109.

Kimoto, M., F. F. Jin, M. Watanabe, and N. Yasutomi, 2001: Zonal-eddy coupling and a neutral mode theory for the Arctic Oscillation. Geophys. Res. Lett., 28, 737-740, https://doi.org/ 10.1029/2000GL012377.

Lorenz, D. J., and D. L. Hartmann, 2003: Eddy-zonal flow feedback in the Northern Hemisphere winter. J. Climate, 16, 1212-1227, https://doi.org/10.1175/1520-0442(2003)16<1212: EFFITN $>2.0 . \mathrm{CO} ; 2$.

Lu, J., G. A. Vecchi, and T. Reichler, 2007: Expansion of the Hadley cell under global warming. Geophys. Res. Lett., 34, L06805, https://doi.org/10.1029/2006GL028443.

- , G. Chen, and D. M. W. Frierson, 2010: The position of the midlatitude storm track and eddy-driven westerlies in aquaplanet AGCMs. J. Atmos. Sci., 67, 3984-4000, https://doi.org/ 10.1175/2010JAS3477.1.
Lucas, C., B. Timbal, and H. Nguyen, 2014: The expanding tropics: A critical assessment of the observational and modeling studies. Wiley Interdiscip. Rev.: Climate Change, 5, 89-112, https://doi.org/10.1002/wcc.251.

Nakamura, T., Y. Tachibana, M. Honda, and S. Yamane, 2006: Influence of the Northern Hemisphere annular mode on ENSO by modulating westerly wind bursts. Geophys. Res. Lett., 33, L07709, https://doi.org/10.1029/2005GL025432.

Nguyen, H., A. Evans, C. Lucas, I. Smith, and B. Timbal, 2013: The Hadley circulation in reanalyses: Climatology, variability, and change. J. Climate, 26, 3357-3376, https://doi.org/10.1175/ JCLI-D-12-00224.1.

Oort, A. H., and J. J. Yienger, 1996: Observed interannual variability in the Hadley circulation and its connection to ENSO. J. Climate, 9, 2751-2767, https://doi.org/10.1175/15200442(1996)009<2751:OIVITH >2.0.CO;2.

Orr, A., T. J. Bracegirdle, J. Scott Hosking, T. Jung, J. D. Haigh, T. Phillips, and W. Feng, 2012: Possible dynamical mechanisms for Southern Hemisphere climate change due to the ozone hole. J. Atmos. Sci., 69, 2917-2932, https://doi.org/ 10.1175/JAS-D-11-0210.1

Palmer, T. N., 1981: Aspects of stratospheric sudden warmings studied from a transformed Eulerian-mean viewpoint. J. Geophys. Res., 86, 9679-9687, https://doi.org/10.1029/ JC086iC10p09679.

- 1982: Properties of the Eliassen-Palm flux for planetary scale motions. J. Atmos. Sci., 39, 992-997, https://doi.org/10.1175/ 1520-0469(1982)039<0992:POTEPF>2.0.CO;2.

Plumb, R. A., 1985: On the three-dimensional propagation of stationary waves. J. Atmos. Sci., 42, 217-229, https://doi.org/ 10.1175/1520-0469(1985)042<0217:OTTDPO > 2.0.CO;2

Polvani, L. M., D. W. Waugh, G. J. P. Correa, and S.-W. Son, 2011: Stratospheric ozone depletion: The main driver of twentiethcentury atmospheric circulation changes in the Southern Hemisphere. J. Climate, 24, 795-812, https://doi.org/10.1175/ 2010JCLI3772.1.

Schmidt, D. F., and K. M. Grise, 2017: The response of local precipitation and sea level pressure to Hadley cell expansion. Geophys. Res. Lett., 44, 10 573-10 582, https://doi.org/10.1002/ 2017GL075380.

Schneider, T., 2006: The general circulation of the atmosphere. Annu. Rev. Earth Planet. Sci., 34, 655-688, https://doi.org/ 10.1146/annurev.earth.34.031405.125144.

Seidel, D. J., and W. J. Randel, 2007: Recent widening of the tropical belt: Evidence from tropopause observations. J. Geophys. Res., 112, D20113, https://doi.org/10.1029/2007JD008861.

Smith, T. M., R. W. Reynolds, T. C. Peterson, and J. Lawrimore, 2008: Improvements to NOAA's historical merged landocean surface temperature analysis (1880-2006). J. Climate, 21, 2283-2296, https://doi.org/10.1175/2007JCLI2100.1.

Son, S.-W., and S. Lee, 2005: The response of westerly jets to thermal driving in a primitive equation model. J. Atmos. Sci., 62, 3741-3757, https://doi.org/10.1175/JAS3571.1.

- N. F. Tandon, L. M. Polvani, and D. W. Waugh, 2009: Ozone hole and Southern Hemisphere climate change. Geophys. Res. Lett., 36, L15705, https://doi.org/10.1029/2009GL038671.

— , and Coauthors, 2010: The impact of stratospheric ozone on Southern Hemisphere circulation changes: A multimodel assessment. J. Geophys. Res., 115, D00M07, https://doi.org/ 10.1029/2010JD014271.

Tao, L., Y. Hu, and J. Liu, 2016: Anthropogenic forcing on the Hadley circulation in CMIP5 simulations. Climate Dyn., 46, 3337-3350, https://doi.org/10.1007/s00382-015-2772-1. 
Thompson, D. W., and J. M. Wallace, 1998: The Arctic Oscillation signature in the wintertime geopotential height and temperature fields. Geophys. Res. Lett., 25, 1297-1300, https:// doi.org/10.1029/98GL00950.

- and - 2000: Annular modes in the extratropical circulation. Part I: Month-to-month variability. J. Climate, 13, 1000-1016, https://doi.org/10.1175/1520-0442(2000)013<1000: AMITEC $>2.0 . \mathrm{CO} ; 2$.

, and G. C. Hegerl, 2000: Annular modes in the extratropical circulation. Part II: Trends. J. Climate, 13, 1018-1036, https:// doi.org/10.1175/1520-0442(2000)013<1018:AMITEC>2.0.CO;2.

- S. Lee, and M. P. Baldwin, 2003: Atmospheric processes governing the Northern Hemisphere annular mode/North Atlantic Oscillation. The North Atlantic Oscillation: Climatic
Significance and Environmental Impact, Geophys. Monogr., Vol. 134, Amer. Geophys. Union, 81-112.

Vallis, G. K., E. P. Gerber, P. J. Kushner, and B. A. Cash, 2004: A mechanism and simple dynamical model of the North Atlantic Oscillation and annular modes. J. Atmos. Sci., 61, 264-280, https://doi.org/10.1175/1520-0469(2004)061<0264: AMASDM $>2.0 . \mathrm{CO} ; 2$.

Walker, C. C., and T. Schneider, 2006: Eddy influences on Hadley circulations: Simulations with an idealized GCM. J. Atmos. Sci., 63, 3333-3350, https://doi.org/10.1175/JAS3821.1.

Waugh, D. W., C. I. Garfinkel, and L. M. Polvani, 2015: Drivers of the recent tropical expansion in the Southern Hemisphere: Changing SSTs or ozone depletion? J. Climate, 28, 6581-6586, https://doi.org/10.1175/JCLI-D-15-0138.1. 